\title{
Handgrip strength, depression, and all- cause mortality in Korean older adults
}

\author{
Soohyun Park', Jinkyung Cho², Donghyun Kim², Youngyun Jin², Inhwan Lee ${ }^{2}$, Haeryun Hong $^{2}$ and \\ Hyunsik Kang ${ }^{2^{*}}$ (D)
}

\begin{abstract}
Background: Decreased muscle strength and/or depression with aging are emerging as important public health concerns in both developed and developing countries. This study investigated the effects of low handgrip strength (HGS) and depression on the risk of all-cause mortality in Korean older adults.

Methods: Data from 13,901 Korean adults (57\% women) who participated in the 2008 baseline survey and completed the 2011 follow-up assessments were used.

Results: In total, the current findings showed that individuals with depression only and individuals with low HGS plus depression had significantly higher risks of all-cause mortality (hazard ratio $(H R)=1.366,95 \%$ confidence interval $(\mathrm{Cl})=1.033-1.807, p=0.029$ and $\mathrm{HR}=1.961,95 \% \mathrm{Cl}=1.409-2.736, p<0.001$, respectively) even after adjustments for all the measured covariates, compared with individuals with high HGS plus no depression $(H R=1)$. Gender-stratified analysis showed that men with depression only and men with depression plus low HGS had significantly higher risks of all-cause mortality $(\mathrm{HR}=1.376,95 \% \mathrm{Cl}=1.029-1.841$, $p=0.031$ and $H R=1.861,95 \% \mathrm{Cl}=1.306-2.651, p=0.001$, respectively) even after adjustments for all the measured covariates, compared with individuals with no depression plus high HGS $(H R=1)$. In women, however, the joint effect of depression and low HGS only remained significant at borderline $(H R=2.603,95 \%$ $\mathrm{Cl}=0.981-6.908, p=0.055)$ when adjusted for all the confounders.
\end{abstract}

Conclusion: The current finding suggested that depression and low HGS were significantly and synergistically associated with the increased risk of premature death from all causes in the Korean geriatric population.

Keywords: Aging, Physical dysfunction, Mental health, Premature death, Geriatrics

\section{Background}

Decreased muscle strength with aging is associated with a number of structural and functional changes that are conducive to increased disability, frailty, and falls [1]. Handgrip strength, a simple bedside tool, was found to be a valid surrogate measure of overall muscular strength [2]. Low handgrip strength predicts all-cause mortality as well as cardiovascular disease (CVD) [3, 4] and cancer mortalities [5]. Yet, low handgrip strength and its relation to the risks of all-cause and cause-specific mortality are modulated by potential confounders,

\footnotetext{
* Correspondence: hkang@skku.edu

${ }^{2}$ Laboratory of Exercise Physiology and Biochemistry, College of Sport Science, Sungkyunkwan University, 2066 Seobu-Ro, Jangan-Gu, Suwon 16419, Republic of Korea

Full list of author information is available at the end of the article
}

including age [6], body mass index [7], nutritional status [5], physical activity [3], and comorbidities [8].

The geriatric mental health is emerging as an important public health concern in both developed and developing countries [9]. In particular, late-life depression (LLD) is one of the most prevalent psychiatric disorders and is associated with morbidity and mortality [10], although this has not been found consistently. This variability may be influenced by gender since women have been consistently reported to be at higher risk of developing depression, with rates of depression for women 1.5 to 2 times those of men [11]. In the Cooperative Health Research in the Region of Augsburg (KORA)-Age Study involving 1066 older adults (mean age $76 \pm 11$ SD years), the risk of low HGS for 3-year all-cause mortality tended to be stronger in women than

(c) The Author(s). 2019 Open Access This article is distributed under the terms of the Creative Commons Attribution 4.0 International License (http://creativecommons.org/licenses/by/4.0/), which permits unrestricted use, distribution, and reproduction in any medium, provided you give appropriate credit to the original author(s) and the source, provide a link to the Creative Commons license, and indicate if changes were made. The Creative Commons Public Domain Dedication waiver (http://creativecommons.org/publicdomain/zero/1.0/) applies to the data made available in this article, unless otherwise stated. 
in men [12]. Contradictory, a systematic review and meta-analysis study involving 2 million men and women showed that low HGS was more strongly associated with increased all-cause mortality risk in men than in women [13]. Other studies also reported gender differences in the relationship between muscular strength and mortality [14]. Together, those previous findings suggest that gender as a moderator may play a role in determining the relationship of low handgrip strength (HGS) and depression with the risk of all-cause mortality in older adults. Furthermore, the mediators linking the mental health to negative health outcomes including premature death are not clear.

Like in Western countries, HGS has been used as an important diagnostic and/or prognostic tool to identify older people with functional limitation and/or at increased risk of age-related diseases in Korea [15]. For example, recent population-based studies showed that low HGS was significantly associated with increased risk of new-onset cognitive dysfunction [16], increased 10-year cardiovascular risk [17], and impaired status of health-related quality of life [18]. Using the sixth Korea National Health and Nutrition Examination Survey (KNHANES VI), Lee et al. [19] showed that low HGS was significantly associated with an increased risk of depression in Korean adults aged $18-80$ years.

To the best of our knowledge, however, no previous study using a population-based design has been attempted to examine the relationships of HGS and LLD with the risk of all-cause mortality stratified by gender in Korean older adults. Therefore, gaining insight into the associations would contribute to the development of new or improved options for the prevention of premature death associated with low HGS and/or depression. This study aimed to investigate whether or not gender modulates the effects of low HGS and depression at baseline on the risk of 3-year all-cause mortality in Korean adults aged 60 years and older.

\section{Methods}

\section{Study design and sample (data source)}

By using data from the 2008 and 2011 Living Profiles of Older People Survey (LPOPS), which is a national wide 3-year longitudinal survey by the Ministry of Health Welfare and Family in Republic of Korea, we conducted a population-based prospective study to evaluate the relationship of low HGS and depression with all-cause mortality in Korean older adults.

The design of the LPOPS has been described previously [20]. In brief, a total of 14,071 older adults aged $\geq 60$ year participated in the 2008 baseline assessment. During the follow-up period, 800 subjects were excluded due to refusal or loss of contact, resulting in 13,901 subjects (43\% men and $57 \%$ women) who were included in the study analysis. The Institutional Review Board (IRB) of the Keimyung University reviewed and approved the study protocol in accordance with the Declaration of Helsinki. All participants provided written informed consent to participate in the survey.

\section{Variables \\ Determination of handgrip strength, depression, and all- cause mortality}

Detailed description of measurement procedures for exposures (i.e., handgrip strength and depression) and outcome (i.e., all-cause mortality) has been published elsewhere [21, 22]. In brief, HGS was measured using a hand grip dynamometer (TANITA No. 6103, Tokyo, Japan). Individual HGS values were divided into age and sex-specific quartiles and categorized as high HGS (upper 50th percentile) or low HGS (lower 50th percentile). The Korean version of the short form of the geriatric depression scale (SGDS-K) was administered as a screening measure for depression, as described in detail elsewhere [23]. All-cause mortality was defined as number of deaths from all causes, as described in detail elsewhere [21, 22].

\section{Determination of confounders}

Body mass index was calculated by dividing body weight $(\mathrm{kg})$ by height squared $\left(\mathrm{m}^{2}\right)$. Socio-demographic (i.e., age, gender, education) and health behavioral factors (i.e., alcohol consumption, smoking, and number of comorbidity and medications) were measured as potential confounders, as described in detail elsewhere [21, 22]. In addition, nutritional status was assessed using the nutrition screening initiative checklist [24]. Disability, cognitive function, and physical activity were assessed using the Korean activities of daily living scale (K-ADL) [25], the Korean version of the mini-mental state examination (MMSE-KC) [26], and the International Physical Activity Questionnaire (IPAQ) short form [27], respectively.

\section{Statistics}

Descriptive statistics were presented as means and standard deviations and frequencies and percentages for continuous and categorical variables, respectively. Independent $\mathrm{t}$-test and Chi-square were used to compare mean differences in continuous and categorical variables, respectively. The Cox proportional hazards model was used to estimate the hazard ratio (HR) and 95\% confidence interval (95\% CI) of handgrip strength and depression for cumulative all-cause mortality. All analyses were performed taking into account complex sampling weights, using SPSS-PC 23.0 (SPSS Inc., Chicago, IL, USA). 
Table 1 Baseline characteristics of study participants

\begin{tabular}{|c|c|c|c|c|}
\hline Parameters & Total $(N=13,901)$ & Men $(N=5996)$ & Women $(N=7905)$ & $p$ value \\
\hline Age (years) & $69.54 \pm 7.06$ & $68.64 \pm 6.53$ & $70.23 \pm 7.36$ & $<0.001$ \\
\hline $\mathrm{BMI}\left(\mathrm{kg} / \mathrm{m}^{2}\right)$ & $23.83 \pm 3.24$ & $23.36 \pm 2.92$ & $24.19 \pm 3.43$ & $<0.001$ \\
\hline \multicolumn{5}{|l|}{ aEducation, n (\%) } \\
\hline $0-3$ years & $3836(27.6)$ & $705(11.8)$ & 3131 (39.6) & \multirow[t]{3}{*}{$<0.001$} \\
\hline $4-6$ years & 4677 (33.6) & $1890(31.5)$ & $2788(35.3)$ & \\
\hline$\geq 7$ years & $5045(36.3)$ & $3288(54.8)$ & $1757(22.2)$ & \\
\hline Income (10,000 won) & $155.94 \pm 185.47$ & $176.07 \pm 203.48$ & $140.67 \pm 168.96$ & $<0.001$ \\
\hline \multicolumn{5}{|l|}{ Marital status, n (\%) } \\
\hline Single/married not living with anyone & $2332(16.8)$ & $357(6.0)$ & $1975(25.0)$ & \multirow[t]{2}{*}{$<0.001$} \\
\hline Married/living with someone & $11,569(83.2)$ & $5639(94.0)$ & $5930(75.0)$ & \\
\hline Past/current smokers, n (\%) & $4617(33.2)$ & $4134(68.9)$ & $483(6.1)$ & $<0.001$ \\
\hline \multicolumn{5}{|l|}{${ }^{\mathrm{b}}$ Alcohol consumption, n (\%) } \\
\hline No drinking & $8734(62.8)$ & $2506(41.8)$ & $6229(78.8)$ & \multirow{2}{*}{$<0.001$} \\
\hline two times a week (or more) & $2394(17.2)$ & 2018 (33.7) & $375(4.8)$ & \\
\hline Nutrition score & $3.15 \pm 3.18$ & $2.80 \pm 2.98$ & $3.42 \pm 3.30$ & $<0.001$ \\
\hline Number of comorbidity & $1.78 \pm 1.50$ & $1.42 \pm 1.32$ & $2.05 \pm 1.57$ & $<0.001$ \\
\hline K-ADL (score) & $7.19 \pm 0.98$ & $7.20 \pm 1.01$ & $7.18 \pm 0.92$ & 0.265 \\
\hline SGDS-K (score) & $4.64 \pm 4.37$ & $3.92 \pm 4.16$ & $5.18 \pm 4.44$ & $<0.001$ \\
\hline MMSE-KC (score) & $24.22 \pm 4.37$ & $25.69 \pm 3.52$ & $23.11 \pm 4.52$ & $<0.001$ \\
\hline Death, n (\%) & $696(5.0)$ & $430(7.2)$ & $266(3.4)$ & $<0.001$ \\
\hline
\end{tabular}

$B M I$ Body mass index, K-ADL Korean Activities of Daily Living, MMSE-KC Korean version of mini-mental state examination, SGDS-K Korean version of 15 -item geriatric depression scale. ${ }^{\mathrm{a}}$ Men $(n=113)$ and women $(n=229)$ had no data available. ${ }^{\mathrm{b}}$ Men $(n=1472)$ and women $(n=1301)$ had no data available

\section{Results}

Table 1 represents the descriptive statistics of the participants in the study. In general, women were older $(P<0.001)$ and less educated $(P<0.001)$ and had higher BMI $(P<0.001)$ than men. Men had higher monthly income $(P<0.001)$, higher MMSE-KC score $(P<0.001)$, lower nutritional risk $(P<0.001)$, lower number of comorbidities, and lower SGD-K score $(P<0.001)$ but were more likely to smoke $(\mathrm{P}<0.001)$ and more likely to consume alcohol $(\mathrm{P}<0.001)$ than women.

Table 2 shows mean values of measured parameters according to handgrip strength level. Older men and women with high HGS were younger $(P=0.043$ and $P<0.001$, respectively), heavier $(P<0.001$ and $\mathrm{P}<0.001$, respectively), more educated $(P<0.001$ and $\mathrm{P}<0.001$, respectively), and more frequently to consume alcohol $(\mathrm{P}<0.001$ and $P=0.019$, respectively) than older men and women with low HGS. Older men and women with high HGS had higher income $(P<0.001$ and $P<0.001$, respectively), higher average MMSE-KC scores $(P<0.001$ and $P<0.001$, respectively), lower number of comorbidities $(P<0.001$ and $P<0.001$, respectively), and higher physical activity $(P<0.001$ and $P<0.001$, respectively) than older men and women with low HGS.

Table 3 shows mean values of measured parameters according to depression status. Depressed older men and women were generally older $(P<001$ and $P<001$, respectively) than non-depressed men and women. Depressed older men had lower BMI $(P=0.004$ and $P=0.047$, respectively), lower income $(P<0.001$ and $P<0.001$, respectively), lower average MMSE-KC score $(P<0.001$ and $P<0.001$, respectively), lower handgrip strength $(P<0.001$ and $P<0.001$, respectively), lower physical activity $(P<0.001$ and $P<0.001$, respectively), higher nutritional risk $(P<0.001$ and $P<0.001$, respectively), and higher number of comorbidities $(P<0.001$ and $\mathrm{P}<0.001$, respectively) but were less educated $(P<0.001$ and $\mathrm{P}<0.001$, respectively) than non-depressed older men and women. Additionally, depressed older men were less frequently to consume alcohol than non-depressed older men $(\mathrm{P}<0.001)$, with no such difference in alcohol consumption observed in women.

Table 4 represents the independent and joint effects of low HGS and presence of depression at baseline on the risk of all-cause mortality stratified by gender. In the total sample, individuals with depression only $(\mathrm{HR}=$ $1.505,95 \% \mathrm{CI}=1.129-2.006, p=0.005)$ or low HGS only $(\mathrm{HR}=1.628,95 \% \mathrm{CI}=1.344-1.973, p<0.001)$ or both exposures $(\mathrm{HR}=3.194,95 \% \mathrm{CI}=2.635-3.871, \mathrm{p}<0.001)$ had significantly higher risk of all-cause mortality, compared with individuals with no depression and high HGS $(H R=1)$. The independent effect of depression only 
Table 2 Comparison of measured parameters according to handgrip strength

\begin{tabular}{|c|c|c|c|c|c|c|}
\hline & \multicolumn{6}{|c|}{ Handgrip strength } \\
\hline & \multicolumn{3}{|l|}{$\overline{M e n}$} & \multicolumn{3}{|l|}{ Women } \\
\hline & Low & High & $P$ value & Low & High & $P$ value \\
\hline $\bar{N}$ & 3130 & 2866 & & 4073 & 3.832 & \\
\hline Age (years) & $68.80 \pm 6.88$ & $68.46 \pm 6.11$ & 0.043 & $70.56 \pm 7.58$ & $69.88 \pm 7.10$ & $<0.001$ \\
\hline $\mathrm{BMI}\left(\mathrm{kg} / \mathrm{m}^{2}\right)$ & $22.90 \pm 2.98$ & $23.84 \pm 2.78$ & $<0.001$ & $23.98 \pm 3.50$ & $24.38 \pm 3.33$ & $<0.001$ \\
\hline \multicolumn{7}{|l|}{ aEducation, n (\%) } \\
\hline $0-3$ years & $462(14.8)$ & $243(8.5)$ & & $1778(43.7)$ & $1353(35.3)$ & \\
\hline $4-6$ years & $1026(32.8)$ & $864(30.1)$ & $<0.001$ & $1382(33.9)$ & $1406(36.7)$ & $<0.001$ \\
\hline$\geq 7$ years & $1567(50.1)$ & $1721(60.0)$ & & $786(19.3)$ & $971(25.3)$ & \\
\hline Income (10,000 won) & $164.70 \pm 174.56$ & $187.49 \pm 215.86$ & $<0.001$ & $135.80 \pm 177.57$ & $144.85 \pm 170.48$ & 0.045 \\
\hline \multicolumn{7}{|l|}{ Marital status, n (\%) } \\
\hline Single/married not living with anyone & $206(6.6)$ & $151(5.3)$ & 0.033 & $1070(26.3)$ & $906(23.6)$ & 0.007 \\
\hline Married/living with someone & $2924(93.4)$ & $2715(94.7)$ & & $3003(73.7)$ & $2927(76.4)$ & \\
\hline Past/current smokers, n (\%) & $2146(68.6)$ & $1987(69.3)$ & 0.539 & $268(6.3)$ & $225(5.9)$ & 0.398 \\
\hline \multicolumn{7}{|l|}{ bAlcohol consumption, n (\%) } \\
\hline No drinking & $1418(45.3)$ & $1087(37.9)$ & $<0.001$ & $3305(81.2)$ & $2924(76.3)$ & 0.019 \\
\hline two times a week (or more) & $980(31.3)$ & $1038(36.2)$ & & $176(4.3)$ & $200(5.2)$ & \\
\hline Nutrition score & $3.23 \pm 3.20$ & $2.38 \pm 2.67$ & $<0.001$ & $3.82 \pm 3.34$ & $3.04 \pm 3.23$ & $<0.001$ \\
\hline Number of comorbidities & $1.55 \pm 1.40$ & $1.29 \pm 1.23$ & $<0.001$ & $2.22 \pm 1.59$ & $1.88 \pm 1.53$ & $<0.001$ \\
\hline K-ADL (score) & $7.34 \pm 1.36$ & $7.06 \pm 0.50$ & $<0.001$ & $7.29 \pm 1.17$ & $7.07 \pm 0.49$ & $<0.001$ \\
\hline SGDS-K (score) & $4.75 \pm 4.54$ & $3.01 \pm 3.49$ & $<0.001$ & $6.08 \pm 4.58$ & $4.25 \pm 4.06$ & $<0.001$ \\
\hline MMSE-KC (score) & $25.11 \pm 3.85$ & $26.39 \pm 2.90$ & $<0.001$ & $22.33 \pm 4.81$ & $23.90 \pm 4.05$ & $<0.001$ \\
\hline Death, n (\%) & $309(9.9)$ & $121(4.2)$ & $<0.001$ & $178(4.4)$ & $88(2.3)$ & $<0.001$ \\
\hline Absolute Handgrip strength (kg) & $26.03 \pm 5.90$ & $36.82 \pm 4.60$ & $<0.001$ & $15.48 \pm 3.68$ & $23.00 \pm 3.70$ & $<0.001$ \\
\hline Relative Handgrip strength (kg/BMl) & $2.22 \pm 0.56$ & $2.99 \pm 0.46$ & $<0.001$ & $1.24 \pm 0.33$ & $1.82 \pm 0.36$ & $<0.001$ \\
\hline Physical activity (Mets/week) & $1677.9 \pm 1885.2$ & $2182.6 \pm 2229.9$ & $<0.001$ & $1127.6 \pm 1428.1$ & $1428.9 \pm 1730.5$ & $<0.001$ \\
\hline
\end{tabular}

For continuous variables, values are mean; $B M I$ Body mass index, $K$ - $A D L$ Korean Activities of Daily Living, MMSE-KC Korean version of mini-mental state examination, SGDS-K Korean version of 15 -item geriatric depression scale. ${ }^{\mathrm{a}}$ Men with low HGS $(n=75)$ and high HGS ( $\left.n=38\right)$ and women with low HGS ( $\left.n=127\right)$ and high HGS $(n=102)$ had no data available. ${ }^{b}$ Men with low HGS $(n=732)$ and high HGS $(n=741)$ and women with low HGS $(n=593)$ and high HGS $(n=708)$ had no data available

$(\mathrm{HR}=1.366,95 \% \mathrm{CI}=1.033-1.807, p=0.029)$ as well as the joint effect of depression plus low HGS (HR $=1.961$, 95\% CI $=1.409-2.736, p<0.001$ ) remained statistically significant even after adjustments for age, sex, BMI, income, education, alcohol consumption, nutritional risk, K-ADL and MMSE scores, and physical activity.

Gender-stratified analysis showed that men with depression only $(\mathrm{HR}=1.682,95 \% \mathrm{CI}=1.107-2.554, p=0.015)$ or low HGS only $(\mathrm{HR}=1.786,95 \% \mathrm{CI}=1.395-2.287, p$ $<0.001)$ or both exposures $(\mathrm{HR}=4.259,95 \% \mathrm{CI}=$ 3.308-5.483, $\mathrm{p}<0.001$ ) had significantly higher risks of all-cause mortality, compared with men with no depression and high HGS $(\mathrm{HR}=1)$. In addition, the independent effect of depression $(\mathrm{HR}=1.376,95 \% \mathrm{CI}=$ $1.029-1.841, p=0.031)$ as well as the joint effect of depression plus low HGS ( $\mathrm{HR}=1.861$, 95\% CI $=1.306-$ $2.651, p=0.001$ ) remained statistically significant even after adjustments for all the measure covariates.
Women with depression only $(\mathrm{HR}=1.597,95 \% \mathrm{CI}=$ $1.070-2.386, p=0.022)$ or low HGS only (HR $=1.394,95 \%$ $\mathrm{CI}=1.026-1.894, p=0.034)$ or both exposures $(\mathrm{HR}=$ $2.670,95 \% \mathrm{CI}=1.985-3.591, p<0.001)$ had significantly higher risks of all-cause mortality, compared with women with no depression plus high HGS $(\mathrm{HR}=1)$. However, the independent effect of depression or low HGS was no longer significant, while the joint effect of both depression and low HGS remained significant at borderline $(\mathrm{HR}=$ 2.603, 95\% CI $=0.981-6.908, p=0.055)$ when adjustments for all the measured covariates.

\section{Discussion}

In this population-based prospective study, we investigated the independent and joint effects of depression and low HGS at baseline on the risk of 3-year all-cause mortality in Korean older adults. Overall, we found that depression independently contributed to increased 
Table 3 Comparison of measured parameters according to depression status

\begin{tabular}{|c|c|c|c|c|c|c|}
\hline & \multicolumn{6}{|l|}{ Depression status } \\
\hline & \multicolumn{2}{|l|}{ Men } & \multirow[b]{2}{*}{$P$ value } & \multicolumn{2}{|l|}{ Women } & \multirow[b]{2}{*}{$P$ value } \\
\hline & Not-depressed & Depressed & & Not-depressed & Depressed & \\
\hline $\mathrm{N}$ & 4816 & 1180 & & 5664 & 2241 & \\
\hline Age (years) & $68.15 \pm 6.24$ & $70.61 \pm 7.23$ & $<0.001$ & $69.33 \pm 7.07$ & $72.51 \pm 7.57$ & $<0.001$ \\
\hline $\mathrm{BMI}\left(\mathrm{kg} / \mathrm{m}^{2}\right)$ & $23.44 \pm 2.84$ & $23.00 .03 \pm 3.27$ & 0.004 & $24.20 \pm 3.34$ & $24.14 \pm 3.64$ & 0.047 \\
\hline \multicolumn{7}{|l|}{ aEducation, n (\%) } \\
\hline $0-3$ years & $471(9.8)$ & $234(19.8)$ & $<0.001$ & 1915 (33.8) & $1216(54.2)$ & $<0.001$ \\
\hline $4-6$ years & $1478(30.7)$ & $412(34.9)$ & & $2113(37.3)$ & $674(30.0)$ & \\
\hline$\geq 7$ years & $2787(57.9)$ & $500(42.4)$ & & $1478(26.1)$ & $278(12.4)$ & \\
\hline Income (10,000 won) & $188.41 \pm 206.03$ & $122.72 \pm 133.09$ & $<0.001$ & $155.01 \pm 1188.88$ & $102.76 \pm 122.40$ & $<0.001$ \\
\hline \multicolumn{7}{|l|}{ Marital status, n (\%) } \\
\hline Single/married not living with anyone & $226(4.7)$ & $131(11.1)$ & $<0.001$ & $1208(21.3)$ & $767(34.2)$ & $<0.001$ \\
\hline Married/living with someone & $4590(95.3)$ & $1050(88.9)$ & & $4456(78.7)$ & $1474(65.8)$ & \\
\hline Past/current smokers, n (\%) & $3228(67.0)$ & $906(76.8)$ & $<0.001$ & $250(4.4)$ & $233(10.4)$ & $<0.001$ \\
\hline \multicolumn{7}{|l|}{ bAlcohol consumption, n (\%) } \\
\hline No drinking & $1879(39.0)$ & $627(53.1)$ & $<0.001$ & 4396 (77.6) & $1833(81.8)$ & $<0.001$ \\
\hline two times a week (or more) & $1691(35.1)$ & $327(27.7)$ & & $265(4.7)$ & $110(4.9)$ & \\
\hline Nutrition score & $2.25 \pm 2.54$ & $5.21 \pm 3.54$ & $<0.001$ & $2.60 \pm 2.79$ & $5.56 \pm 3.55$ & $<0.001$ \\
\hline Number of comorbidity & $1.31 \pm 1.27$ & $1.91 \pm 1.44$ & $<0.001$ & $1.87 \pm 1.52$ & $2.52 \pm 1.60$ & $<0.001$ \\
\hline K-ADL (score) & $7.08 \pm 0.58$ & $7.65 \pm 1.91$ & $<0.001$ & $7.09 \pm 0.57$ & $7.40 \pm 1.40$ & $<0.001$ \\
\hline SGDS-K (score) & $2.21 \pm 2.33$ & $10.94 \pm 2.23$ & $<0.001$ & $2.87 \pm 2.53$ & $11.06 \pm 2.23$ & $<0.001$ \\
\hline MMSE-KC (score) & $26.21 \pm 3.01$ & $23.72 \pm 4.46$ & $<0.001$ & $23.95 \pm 4.05$ & $20.90 \pm 4.93$ & $<0.001$ \\
\hline Death, n (\%) & $249(5.2)$ & $181(15.3)$ & $<0.001$ & $144(2.5)$ & $122(5.4)$ & $<0.001$ \\
\hline Absolute Handgrip strength (kg) & $32.12 \pm 7.15$ & $27.30 \pm 8.01$ & $<0.001$ & $19.98 \pm 5.12$ & $16.94 \pm 5.04$ & $<0.001$ \\
\hline Relative Handgrip strength (kg/BMl) & $2.66 \pm 0.61$ & $2.32 \pm 0.70$ & $<0.001$ & $1.59 \pm 0.44$ & $1.36 \pm 0.44$ & $<0.001$ \\
\hline Physical activity (Mets/week) & $2122.6 \pm 2148.0$ & $1079.2 \pm 1242.7$ & $<0.001$ & $1418.7 \pm 1684.8$ & $907.2 \pm 1242.7$ & $<0.001$ \\
\hline
\end{tabular}

For continuous variables, values are mean; BMI Body mass index, K-ADL Korean Activities of Daily Living, MMSE-KC Korean version of mini-mental state examination, SGDS-K Korean version of 15 -item geriatric depression scale. ${ }^{a}$ Men with no depression $(n=80)$ and depression $(n=34)$ and women with no depression $(n=156)$ and depression $(n=73)$ had no data available. ${ }^{\mathrm{b}}$ Men with no depression $(n=1246)$ and depression $(n=226)$ and women with no depression $(n=1003)$ and depression $(n=298)$ had no data available

all-cause mortality risk in Korean older adults, and the increased all-cause mortality risk was exacerbated by presence of low HGS at baseline. However, our gender-stratified analysis showed that the independent and joint effects of depression and low HGS were only the case for men. In women, the independent effect of depression and low HGS on the risk of all-cause mortality was not observed at statistical significance level, while the joint effect of the exposures remained significant at borderline even after adjustments for all the covariates. Together, the current findings suggest that depression as well as depression plus low HGS are significantly associated with increased all-cause mortality risk in Korean older adults.

With respect to depression, the current findings support and extend those of previous studies reporting gender difference in the association between depression and all-cause mortality in older adults. In a sample of community-living elderly men and women, Schoevers et al. [26] showed that major depressive symptoms was significantly associated with the increased risk of premature death in both men and women. However, the association between minor depressive symptoms and death was found only in men. In a prospective cohort study of 3701 men and women aged > 70 years, Penninx et al. [27] found that newly depressed men were at increased risk of cardiovascular morbidity and mortality, but that women were not. In a large community-based elderly population, Ryan et al. [28] investigated the association between depression and mortality stratified by the use of antidepressants and the severity of depression. In that study, they found that in men, using antidepressants contributed to increased mortality risk according to the severity of depression in a dose-response manner. In women, only the severity of depression in the absence of antidepressants was positively associated with the risk of 
Table 4 Independent and joint effects of handgrip strength and depression on all-cause mortality stratified by sex

\begin{tabular}{|c|c|c|c|c|c|c|}
\hline \multirow[t]{2}{*}{ Gender } & \multicolumn{2}{|l|}{ Exposures } & \multirow[t]{2}{*}{ Crude HR (95\% Cl) } & \multirow[t]{2}{*}{$P$ value } & \multirow[t]{2}{*}{ Adjusted HR $(95 \% \mathrm{Cl})^{\mathrm{a}}$} & \multirow[t]{2}{*}{$P$ value } \\
\hline & Low HGS & Depression & & & & \\
\hline \multirow[t]{4}{*}{ Total } & Negative & Negative & 1 & & 1 & \\
\hline & Negative & Positive & $1.505(1.129 \sim 2.006)$ & 0.005 & $1.366(1.033 \sim 1.807)$ & 0.029 \\
\hline & Positive & Negative & $1.628(1.344 \sim 1.973)$ & $<0.001$ & $1.208(0.782 \sim 1.866)$ & 0.394 \\
\hline & Positive & Positive & $3.194(2.635 \sim 3.871)$ & $<0.001$ & $1.961(1.409 \sim 2.736)$ & $<0.001$ \\
\hline \multirow[t]{4}{*}{ Men } & Negative & Negative & 1 & & 1 & \\
\hline & Negative & Positive & $1.682(1.1 .07 \sim 2.554)$ & 0.015 & $1.376(1.029 \sim 1.841)$ & 0.031 \\
\hline & Positive & Negative & $1.786(1.395 \sim 2.287)$ & $<0.001$ & $1.120(0.694 \sim 1.807)$ & 0.643 \\
\hline & Positive & Positive & $4.259(3.308 \sim 5.483)$ & $<0.001$ & $1.861(1.306 \sim 2.651)$ & 0.001 \\
\hline \multirow[t]{4}{*}{ Women } & Negative & Negative & & & 1 & \\
\hline & Negative & Positive & $1.597(1.070 \sim 2.386)$ & 0.022 & $0.763(0.250 \sim 2.325)$ & 0.634 \\
\hline & Positive & Negative & $1.394(1.026 \sim 1.894)$ & 0.034 & $1.339(0.440 \sim 4.073)$ & 0.607 \\
\hline & Positive & Positive & $2.670(1.985 \sim 3.591)$ & $<0.001$ & $2.603(0.981 \sim 6.908)$ & 0.055 \\
\hline
\end{tabular}

HR Hazard ratio, $\mathrm{Cl}$ Confidence interval, $H G S$ Handgrip strength. $\mathrm{HR}^{\mathrm{a}}$ adjusted for age, sex, $\mathrm{BMI}$, income, education, smoking, alcohol consumption, nutritional risk, comorbidities, K-ADL and MMSE scores, and physical activity

mortality. On the other hand, by analyzing data obtained from the New Haven cohort $(N=2812)$ of the Established Populations for the Epidemiologic Studies of the Elderly (EPESE) project, Mendes de Leon et al. [29] found that depressed women were at increased risk of coronary heart disease (CHD) mortality and CHD events, but men were not. In a review paper, Sevick and colleagues [30] showed that there is no evidence to support a gender-specific association of depression with major health outcomes in older adults. Together, the gender difference in the independent and joint effects of depression and low HGS on the risk of all-cause mortality observed in the current study should be confirmed in a future study that includes the severity of depressive symptoms, antidepressants, and others as potential confounders.

Several explanations can be given for gender difference in the all-cause mortality risk of depression. First, the gender difference may result from cultural, social, behavioral or adaptive differences between men and women. Women are more likely to report symptoms and distress than men [31], thereby seeking medical treatment. On the other hand, depression is less likely to be recognized and treated in men [32], and therefore the presence of detectable depression in men may signify a more extreme condition [33], accounting for the stronger association with premature death. Second, difference in the nature or intensity of exposure to risk factors or in the vulnerability to the same risk factors may contribute to gender difference in the association between depression and all-cause mortality [28]. Third, genetic and biological factors may some role in the emergence of gender differences in depression and its relation to all-cause mortality [34]. Lastly, in older adults with depression, men are more likely to die and women to be first disabled, which should be tested in a longer follow-up study.
With respect to HGS, the current findings of the study support and extend those of previous studies reporting an inverse association between HGS and the risks of all-cause and cause-specific mortalities in older adults. By analyzing data obtained from a prospective urban-rural epidemiology study involving 139,691 adults aged 35-70 years from 17 countries, Leong et al. [5] showed that HGS was inversely and significantly associated with all-cause mortality $(\mathrm{HR}=1.16$ and $95 \% \mathrm{CI}=$ $1.13-1.20)$, cardiovascular mortality $(\mathrm{HR}=1.17$ and $95 \%$ $\mathrm{CI}=1.11-1.24)$, non-cardiovascular mortality $(\mathrm{HR}=1.17$ and $95 \% \mathrm{CI}=1.12-1.21)$, myocardial infarction $(\mathrm{HR}=$ 1.07 and $95 \% \mathrm{CI}=1.02-1.11)$ and stroke $(\mathrm{HR}=1.09$ and $95 \% \mathrm{CI}=1.05-1.15)$ during 4 years of follow-up. In a population-based longitudinal cohort study involving 6850 men (42\%) and women (58\%) aged 50-80 years, Strand et al. [35] showed that weak HGS at baseline was significantly and positively associated with all-cause and cause-specific mortalities during 17 years of follow-up. In a systematic review, Bohannon [36] also showed that low HGS was consistently and significantly associated with premature mortality, disability, and other health-related complications in middle-aged and older adults. In the cooperative health research involving 1066 individuals aged $76 \pm 11$ years, Arvandi et al. [37] showed that low HGS was significantly associated with increased all-cause mortality risk during > 3 years of follow-up, and women with low HGS had higher all-cause mortality risk than men with low HGS.

Several explanations can be given for the association between low HGS and all-cause mortality risk. Firstly, depression is associated with low HGS, together contributing to increased all-cause mortality risk additively. Secondly, low HGS is significantly associated with 
increased morbidities of chronic diseases, thereby contributing to increased all-cause mortality risk additively. Thirdly, low HGS may reflect frailty since it is a key component of its phenotype. Frail older adults are less likely to get a chance of medication and/or medical treatments [38] when they are necessary, contributing to increased risk of dying prematurely from all causes. Lastly, low HGS may be the end stage of a cascade of events from inflammatory processes to coagulative dysregulation to a range of alterations in hormones and peptides and thereby a threshold state characterized by increasing inability to adequately address physiological demands or a disruption of homeostatic mechanisms.

Taken together, those findings showed that depression and low HGS contributed to increased all-cause mortality in an addictive manner in older men but not in older women, implying a gender difference in the relationship of depression and low HGS with the risk of premature death from all causes in Korean geriatric population. Yet, the mechanism(s) underlying the gender difference in the impacts of the two exposures on the risk of all-cause mortality remains to be elucidated.

The present study have some strengths. First, study participants were a representative sample of Korean older populations, as described elsewhere [21, 22]. Second, the mortality data were gathered from a reliable register. Third, many covariates as possible were assessed in order to obtain a more reliable and reproducible association between the exposures and mortality. However, some limitations of the study must be also acknowledged. First, any causal inference regarding the pathologic mechanism(s) linking low HGS and depression to all-cause mortality cannot be possible due to the cross-sectional nature of the present study. Second, biomarkers including inflammatory cytokines and hormones associated with loss of muscle mass and/or depression were not available in this study. Third, depression differently modulates the association between low HGS and all-cause mortality, especially among young-old adults [39].

\section{Conclusion}

In summary, low HGS and depression are important public health problems due to their devastating consequences. In this study, we found that depression and low HGS were significantly associated with increased allcause mortality risk in Korean older adults, suggesting that a multidimensional effort to deal with physical dysfunction and mental health is likely to be more relevant to mortality in Korean geriatric population In men, both independent and joint effects of depression and low HGS were significantly associated with the increased risk of all-cause mortality independent of all the covariates. Likewise, both depression and low HGS were also significantly and synergistically associated with increased all-cause mortality risk in women. Yet, the joint effect of the exposures only remained significant at borderline when adjusted for all the covariates. Considering the cross-sectional nature of the study, however, a further study will be necessary to investigate how the covariates influence the independent and joint effects of low HGS and depression on all-cause mortality in a cause- and-effect manner in Korean older adults.

\section{Abbreviations}

CHD: Coronary heart disease; CVD: Cardiovascular disease; EPESE: Established Populations for the Epidemiologic Studies of the Elderly; HGS: Handgrip strength; HR: Hazard ratio; IPAQ: International Physical Activity Questionnaire; K-ADL: Korean activities of daily living scale; LLD: Late life depression; LPOPS: Living Profiles of Older People Survey; MMSE-KC: Korean version of the mini-mental state examination; SGDS-K: Korean version of the short form of the geriatric depression scale

\section{Acknowledgements}

We gratefully thank the Korea Institute for Health and Social Affairs for allowing use of their data for this study.

\section{Funding}

This work was supported by the National Research Foundation Grant funded by the Korean Government (NRF-2018R1D1A1B07048153 and NRF2016R1A6A3A11932432). The funders had no role in study design, data collection and analysis, decision to publish, or preparation of the manuscript.

\section{Availability of data and materials}

Data from the LPOPS study are available upon request to researchers who meet the criteria for access to confidential information. Access to data is permitted by Korea Institute for Health and Social Affairs and requests to access data may be submitted to Hyunsik Kang, PhD (hkang@skku.edu).

\section{Authors' contributions}

HK contributed to the conception and design, data analysis, data interpretation, and writing of the manuscript. SP contributed to preparation of data, statistical analysis, interpretation of data, and preparing of the manuscript. JC, DK, YJ, IL, and $\mathrm{HH}$ equally contributed to assisting of statistical analysis, searching for the literature, and preparing of the manuscript. All authors read and approved the final manuscript.

Ethics approval and consent to participate

Prior to the interview, written informed consent was given by all participants of the LPOPS survey. The data were anonymized and de-identifiable with no personal information, with careful protection on confidentiality. The Institutional Review Board (IRB) of the Keimyung University reviewed and approved the study protocol in accordance with the Declaration of Helsinki.

Consent for publication

No applicable.

Competing interests

All the authors declare that they have no competing interests.

\section{Publisher's Note}

Springer Nature remains neutral with regard to jurisdictional claims in published maps and institutional affiliations.

\section{Author details}

'Department of Sports Science, Korea Institute of Sport Science, Seoul, Republic of Korea. 'Laboratory of Exercise Physiology and Biochemistry, College of Sport Science, Sungkyunkwan University, 2066 Seobu-Ro, Jangan-Gu, Suwon 16419, Republic of Korea. 
Received: 22 August 2018 Accepted: 18 April 2019

Published online: 03 May 2019

\section{References}

1. Baumgartner RN, Koehler KM, Gallagher D, Romero L, Heymsfield SB, Ross RR, et al. Epidemiology of sarcopenia among the elderly in New Mexico. Am J Epidemiol. 1998;147:755-63.

2. Bohannon RW. Dynamometer measurements of hand-grip strength predict multiple outcomes. Percept Mot Skills. 2001;93:323-8.

3. Karlsen T, Nauman J, Dalen H, Langhammer A, Wisløff U. The combined association of skeletal muscle strength and physical activity on mortality in older women: the HUNT2 study. Mayo Clin Proc. 2017;92:710-8.

4. Yates T, Zaccardi F, Dhalwani NN, Davies MJ, Bakrania K, Celis-Morales CA, et al. Association of walking pace and handgrip strength with all-cause, cardiovascular, and cancer mortality: a UK biobank observational study. Eur Heart J. 2017;38:3232-40.

5. Leong DP, Teo KK, Rangarajan S, Lopez-Jaramillo P, AJr A, Orlandini A, et al. Prognostic value of grip strength: findings from the prospective urban rural epidemiology (PURE) study. Lancet. 2015;386:266-73.

6. Rijk JM, Roos PR, Deckx L, van den Akker M, Buntinx F. Prognostic value of handgrip strength in people aged 60 years and older: a systematic review and meta-analysis. Geriatr Gerontol Int. 2016;6:5-20.

7. Kim Y, Wijndaele K, Lee DC, Sharp SJ, Wareham N, Brage S. Independent and joint associations of grip strength and adiposity with all-cause and cardiovascular disease mortality in 403,199 adults: the UK biobank study. Am J Clin Nutr. 2017:106:773-82.

8. Celis-Morales CA, Petermann F, Hui L, Lyall DM, lliodromiti S, McLaren J, et al. Associations between diabetes and both cardiovascular disease and allcause mortality are modified by grip strength: evidence from UK biobank, a prospective population-based cohort study. Diabetes Care. 2017:40:1710-8

9. WHO. Mental health atlas 2014. www.who.int/mental_health/evidence/atlas/ mental_health_atlas_2014/en/. Accessed 1 May 2018.

10. Georgakis MK, Papadopoulos FC, Protogerou AD. Comorbidity of cognitive impairment and late-life depression increase mortality: results from a cohort of community-dwelling elderly individuals in rural Greece. J Geriatr Psychiatry Neurol. 2016;29:195-204.

11. Forsell $Y$, Winblad $B$. Incidence of major depression in a very elderly population. Int J Geriatr Psychiatry. 1999;14:368-72.

12. Arvandi M, Strasser B, Meisinger C, Volaklis K, Gothe RM, Siebert U, et al. Gender differences in the association between grip strength and mortality in older adults: results from the KORA-age study. BMC Geriatr. 2016;16(1):201.

13. García-Hermoso A, Cavero-Redondo I, Ramírez-Vélez R, Ruiz JR, Ortega FB, Lee DC, et al. Muscular strength as a predictor of all-cause mortality in an apparently health population: a systematic review and meta-analysis of data from approximately 2 million men and women. Arch Phys Med Rehabil. 2018:99(10):2100-13.

14. Guadalupe-Grau A, Carnicero JA, Gomez-Cabello A, Gutierrez Avila G, Humanes $S$, Alegre LM, et al. Association of regional muscle strength with mortality and hospitalisation in older people. Age Ageing. 2015;44(5):790-5.

15. Kim CR, Jeon YJ, Kim MC, Jeong T, Koo WR. Reference values for hand grip strength in the south Korean population. PLoS One. 2018;13(4):e0195485.

16. Jeong S, Kim J. Prospective association of handgrip strength with risk of new-onset cognitive dysfunction in Korean adults: a 6-year national cohort study. Tohoku J Exp Med. 2018;244(2):83-91.

17. Lee MR, Jung SM, Kim HS, Kim YB. Association of muscle strength with cardiovascular risk in Korean adults: findings from the Korea National Health and nutrition examination survey (KNHANES) VI to VII (2014-2016). Medicine (Baltimore). 2018;97(47):e13240.

18. Lee MR, Jung SM, Bang H, Kim HS, Kim YB. The association between muscular strength and depression in Korean adults: a cross-sectional analysis of the sixth Korea National Health and nutrition examination survey (KNHANES VI) 2014. BMC Public Health. 2018;18(1):1123.

19. OK BT, Hwang YS, Lee JY, Park SK, Hong SW, Suh YS, Kim DH. Factors related with hand grip strength in Korean elderly. Korean J Clin Geri. 2017; 18(1):22-9.

20. Roh HW, Hong CH, Lee Y, Oh BH, Lee KS, Chang K, et al. Participation in physical, social, and religious activity and risk of depression in the elderly: a community-based three-year longitudinal study in Korea. PLoS One. 2015; 10:e0132838.

21. Cho J, Lee I, Park S, Jin Y, Kim D, Kim S, Kang H. Physical activity and allcause mortality in Korean older adults. Ann Hum Biol. 2018;45:337-45.
22. Park SH, Kim D, Cho J, Jin Y, Lee I, Lee K, Kang H. Depressive symptoms and all-cause mortality in Korean older adults: a 3-year population-based prospective study. Geriatr Gerontol Int. 2018;186:950-6.

23. Bae JN, Cho MJ. Development of the Korean version of geriatric depression scale and its short form among elderly psychiatric patients. J Psychosom Res. 2004:57:297-305.

24. Posner BM, Jette AM, Smith KW, Miller DR. Nutrition and health risks in the elderly: the nutrition screening initiative. Am J Public Health. 1993:83:972-8.

25. Won CW, Yang KY, Rho YG, Kim SY, Lee EJ, Yoon JL, et al. The development of Korean activities of daily living (K-ADL) and Korean instrumental activities of daily living (K-IADL) scale. J Korean Geriatr Soc. 2002;6:107-20.

26. Lee JH, Lee KU, Lee DY, Kim KW, Jhoo JH, Kim JH, et al. Development of the Korean version of the consortium to establish a registry for Alzheimer's disease assessment packet (CERAD-K): clinical and neuropsychological assessment batteries. J Gerontol B Psychol Sci Soc Sci. 2002;57:P47-53.

27. Kurtze R, Rangul V, Hustvedt BE. Reliability and validity of the international physical activity questionnaire in the Nord-Trøndelag health study (HUNT) population of men. BMC Med Res Methodol. 2008;8:63.

28. Schoevers RA, Geerlings MI, Beekman AT, Penninx BW, Deeg DJ, Jonker C, et al. Association of depression and gender with mortality in old age. Results from the Amsterdam study of the elderly (AMSTEL). Br J Psychiatry. 2000; 177:336-42.

29. Penninx BW, Guralnik JM, Mendes de Leon CF, Pahor M, Visser M, et al. Cardiovascular events and mortality in newly and chronically depressed persons > 70 years of age. Am J Cardiol. 1998;81:988-94.

30. Ryan J, Carriere I, Ritchie K, Stewart R, Toulemonde G, Dartigues JF, et al. Late-life depression and mortality: influence of gender and antidepressant use. Br J Psychiatry. 2008;192:12-8.

31. Mendes de Leon CF, Krumholz HM, Seeman TS, Vaccarino V, Williams CS, Kasl SV, et al. Depression and risk of coronary heart disease in elderly men and women: New Haven EPESE, 1982-1991. Established populations for the epidemiologic studies of the elderly. Arch Intern Med. 1998;158:2341-8.

32. Sevick MA, Rolih C, Pahor M. Gender differences in morbidity and mortality related to depression: a review of the literature. Aging (Milano). 2000;12: 407-16.

33. Kornstein SG, Sloan DM, Thase ME. Gender-specific differences in depression and treatment response. Psychopharmacol Bull. 2002;36:99-112.

34. Crawford MJ, Prince M, Menezes $P$, Mann AH. The recognition and treatment of depression in older people in primary care. Int J Geriatr Psychiatry. 1998;13:172-6.

35. Gorman JM. Gender differences in depression and response to psychotropic medication. Gend Med. 2006:3:93-109.

36. Lemogne C, Niedhammer I, Khlat M, Ravaud JF, Guillemin F, Consoli SM, et al. Gender differences in the association between depressive mood and mortality: a 12-year follow-up population-based study. J Affect Disord. 2012; 136:267-75.

37. Strand BH, Cooper R, Bergland A, Jørgensen L, Schirmer H, Skirbekk V, et al. The association of grip strength from midlife onwards with all-cause and cause-specific mortality over 17 years of follow-up in the Tromsø study. J Epidemiol Community Health. 2016:70:1214-21.

38. Bohannon RW. Hand-grip dynamometry predicts future outcomes in aging adults. J Geriatr Phys Ther. 2008;31:3-10.

39. Kimbro LB, Mangione CM, Steers WN, Duru OK, McEwen L, Karter A, et al. Depression and all-cause mortality in persons with diabetes mellitus: are older adults at higher risk? Results from the translating research into action for diabetes study. J Am Geriatr Soc. 2014;62:1017-22.

Ready to submit your research? Choose BMC and benefit from:

- fast, convenient online submission

- thorough peer review by experienced researchers in your field

- rapid publication on acceptance

- support for research data, including large and complex data types

- gold Open Access which fosters wider collaboration and increased citations

- maximum visibility for your research: over $100 \mathrm{M}$ website views per year

At $\mathrm{BMC}$, research is always in progress.

Learn more biomedcentral.com/submission 